\title{
Ethical considerations and interdisciplinary approach to research on COVID-19 pandemic: The response of Iran University of Medical Sciences
}

\author{
Akram Hashemi ${ }^{1}$, Fatemeh Bahmani ${ }^{1}$, Saeedeh saeedi Tehrani ${ }^{1}$, Mina Forouzandeh ${ }^{1}$, Jalil Koohpayehzadeh ${ }^{2}$, \\ Mortaza Ashrafi ${ }^{1}$, Majid Reza Khalajzadeh ${ }^{1}$, Seyed Abbas Motevalian* $*^{3}$ (D)
}

Received: 4 Jun 2020

Published: 29 Jul 2020

\section{Abstract}

Background: Research ethics committees are comprised of policymakers, supervisors, and decision-makers and aim at increasing adherence to professional ethics standards in conducting health-related research. The existential philosophy of these committees is to preserve the patients' health, maintain and promote public trust in health care providers, protect the rights of both patients and health care providers, and promote organizational ethics.

However, this task can be complex and challenging during a public health emergency. Research ethics committees set the standard of research in the emergency situations through defining which research has the potential to promote the quality of response to a public health emergency.

Methods: This study aims at collecting and classifying the valuable experiences of the research ethics committee members and reviewers during the early days of the COVID-19 epidemic in Iran University of Medical Sciences, one of the major universities in Tehran. It provides a basic understanding of the key concepts and challenges in reviewing and approving research by research ethics committees and the recommendations to overcome these challenging issues.

Results: To accelerate the review process of COVID-19 research proposals, the scientific, methodologic and ethics review panel was integrated as a large committee called 'IUMS COVID-19 research committee' The first meeting was held on March 7, two weeks after the official announcement of the first case of the disease and, as of the writing of this article, is being held once a week. A total of 130 projects have been discussed and evaluated in this committee, among which 83 proposals were approved after modification.

Conclusion: An interdisciplinary approach supports a flexible and effective scientific and ethics review of research leading to more protection of research subjects as well as promotion in the treatment and management of the pandemic ahead.

Keywords: Research ethics committee, Pandemic, COVID-19

Conflicts of Interest: Jalil Koohpayehzadeh holds the position of the Chancellor of the Iran University of Medical Sciiences \& Seyed Abbas Motevalian holds the position of the Vice-Chancellor for Research and Technology at the Iran University of Medical Sciences. The rest of the authors declare that there is no conflict of interest.

Funding: None

\section{*This work has been published under CC BY-NC-SA 1.0 license.}

Copyright $\odot$ Iran University of Medical Sciences

Cite this article as: Hashemi A, Bahmani F, Saeedi Tehrani S, Forouzandeh M, Koohpayehzadeh J, Ashrafi M, Khalajzadeh MR, Motevalian SA. Ethical considerations and interdisciplinary approach to research on COVID-19 pandemic: The response of Iran Univiersity of Medical Sciences. Med J Islam Repub Iran. 2020 (29 Jul);34:87. https://doi.org/10.34171/mjiri.34.87

\section{Introduction}

Following the COVID-19 pandemic crisis, the Director

Corresponding author: Dr Seyed Abbas Motevalian, amotevalian@yahoo.com

1. Department of Medical Ethics, School of Medicine, Iran University of Medical Sciences, Tehran, Iran

2. Community Medicine Department, Faculty of Medicine, Iran University of Medical Sciences, Tehran, Iran

3. Research Center for Addiction and Risky Behaviors (ReCARB), Psychosocial Health Research Institute (PHRI), Iran University of Medical Sciences, Tehran, Iran of Public Relations and Information Department at the

\section{$\uparrow$ What is "already known" in this topic:}

Research conducted during global health emergencies raises particularly complex ethical challenges and there are a few research ethics guidelines, providing general recommendations on how research ethics committees should address these challenges.

\section{$\rightarrow$ What this article adds:}

This report presents the experience of Iran University of Medical Sciences in ethically managing research during early COVID-19 outbreak in Iran and provides a context-based guide to improve emergency response and preparedness regarding future outbreaks. 
Ministry of Health and Medical Education (MOHME) formally announced the death of the first patient with coronavirus-2019 in Qom on Wednesday February 19, 2020, and Iran's involvement was officially declared (1).

As the disease spread in the country, the headquarters for fighting Coronavirus convened on Thursday, March 1, 2020 with the membership composition of the minister, his deputies, and other senior managers of the MOHME $(2,3)$.

Six days later, the MOHME published the first "Guidelines on the care, diagnosis, and treatment of Coronavirus."

What matters most in health-related crises is evidencebased decision-making. Conducting research to generate such evidences in epidemics, provided that ethical considerations are fully taken into account, is an undeniable necessity.

As one of the most renowned medical universities in the country, Iran University of Medical Sciences (IUMS) plays an effective role in providing educational, research, and medical services in Tehran province.

There are 17 hospitals - 11 teaching and 6 nonteaching hospitals - affiliated to the university, covering over 5350000 of the population of Tehran province, with more than 12 million habitants. The university owns 3300 university hospital beds and there are about 7000 additional beds in the private covered centers. Thus, a total of 10000 hospital beds, located in southwest, west, and northwest of Tehran, are supervised by the IUMS. The university has more than 9000 students, about 1000 faculty members, 46 research centers, and 4 research institutes.

The university's Vice-Chancellor for Research and Technology established "IUMS COVID-19 research committee" at Iran University of Medical Sciences in early March, stressing that in this pandemic, research should play an essential role in providing scientific evidence as well as new technologies to support clinicians, nurses, health professionals, and wider range of policy-makers who should make important decisions in response to novel Coronavirus epidemic.

\section{Methods}

The IUMS COVID-19 research committee started activities since the same day it was established. Working with the members of the research ethics committee of IUMS and the members of the university's department of medical ethics, the committee was determined to provide maximal protection for patients and individuals involved in these projects. The committee is consisted of three groups: (1) relevant university managers, including university chancellor and vice chancellors, CEOs of 4 university hospitals involved with COVID-19 patients; (2) three members of the research ethics committee of IUMS; and (3) university faculty members from various disciplines/departments, including medical virology, immunology, infectious disease and tropical medicine, internal medicine/pulmonology, emergency medicine, psychiatry, community medicine, anesthesiology, epidemiology, biostatistics, occupational and environmental health, medical informatics, disaster management, health economy, health system management, and health policy.

The COVID-19 research topics can be divided into 2 categories:

Group 1: Projects that are performed to answer the clinical and managerial questions raised by professionals and policymakers, and the answer needs to be presented to them as soon as possible for their decision-making.

Group 2: Projects that are expected to document the epidemic experience in Iran and share them with the world.

Below are the operations performed by the committee:

1. The first meeting of the IUMS COVID-19 research committee was held on Saturday, March 17, 2020; as of the writing of the current paper, 6 meetings have been convened in-person and several meetings are held virtually.

2. The committee usually exchanges information through emails and social networks and holds its meetings once a week.

3. Despite expediting the process of evaluating the projects on Coronavirus, the process of reviewing and approving the projects is done with strict compliance with the quality criteria.

4. four main working groups have been set up to manage research on COVID-19, including (1) research on epidemiology and public health, (2) clinical research, and (3) basic science and virology research, and finally, (4) Research into staff health maintenance, particularly mental and educational health. In meetings and via social networks, the 4 groups discuss relevant research proposals.

5. After the scientific review of the proposals at these meetings, all research proposals are forwarded to research ethics professionals for review within 48 hours.

6. Proposals can obtain research ethics committee certificate only if the researchers have properly followed the recommendations of the reviewers, in accordance with national and international guidelines for ethics in research.

7. All research projects are recorded at the website of Iran National Committee for Ethics in Biomedical Research and subsequently will be accessible to the public.

8. If the National Committee for Ethics determines ethical considerations have not been fully met in the approval of a research project, it shall suspend the implementation of the project and revoke the issued research ethics committee certificate after coordinating with the committee for research ethics of the approving university.

9. Challenges and strategies of ethics reviewers presented in the Coronavirus Epidemic Plans 2019 are summarized in Table 1.

\section{Results}

Considering importance of the issue, the research committee meetings were held on March $7^{\text {th }}, 14^{\text {th }}, 8^{\text {th }}, 25^{\text {th }}, 30^{\text {th }}$ and on April 11th and 21st of 2020, and they are continued at least once a week. As of the writing of this article (April 21, 2020), 130 projects have been discussed in this committee, of which 7 were rellated to mental health, 32 to epidemiological and public health, 28 to clinical research, and 16 to basic science and virology. These data are presented in Table 2

Also, according to the views and recommendations of 
Table 1. concerns of ethics reviewers and recommendations

\begin{tabular}{|c|c|c|}
\hline Research ethics criteria & Reviewer/committee concern & Recommended solutions \\
\hline \multirow[t]{2}{*}{ Scientific design } & $\begin{array}{l}\text { Previous scientific evidence is insufficient (Clinical } \\
\text { information or pharmaceutical mechanism has not } \\
\text { been fully disclosed.). }\end{array}$ & $\begin{array}{l}\text { Evaluation of clinical information and pharmaceutical } \\
\text { mechanisms by scientific reviewers of the research } \\
\text { ethics committee. }\end{array}$ \\
\hline & $\begin{array}{l}\text { The objectives are hardly achievable with respect to } \\
\text { available facilities. }\end{array}$ & $\begin{array}{l}\text { Assessing the feasibility of proposed research proce- } \\
\text { dures by the research ethics committee. }\end{array}$ \\
\hline Inclusion and exclusion criteria & $\begin{array}{l}\text { Failure to meet appropriate inclusion and exclusion } \\
\text { criteria. }\end{array}$ & $\begin{array}{l}\text { The criteria are to be explained in an objective and } \\
\text { measurable way in both control and case groups. }\end{array}$ \\
\hline \multirow[t]{3}{*}{ Research procedures } & $\begin{array}{l}\text { Absence of adequate or appropriate expertise to } \\
\text { perform the research procedures. }\end{array}$ & $\begin{array}{l}\text { Adding a researcher with relevant expertise to the re- } \\
\text { search group. }\end{array}$ \\
\hline & $\begin{array}{l}\text { Not including procedures to monitor adverse events } \\
\text { of the research interventions. }\end{array}$ & $\begin{array}{l}\text { Including procedures to monitor adverse events of the } \\
\text { research interventions. }\end{array}$ \\
\hline & $\begin{array}{l}\text { Absence of procedures for post-trial provision of } \\
\text { research interventions, such as special psychological } \\
\text { or educational training for the control group. }\end{array}$ & Employing procedures for post trial provisions. \\
\hline \multirow[t]{3}{*}{ Risk/burden and benefit } & $\begin{array}{l}\text { Failure to provide evidence on efficacy and safety } \\
\text { required for therapeutic intervention. }\end{array}$ & $\begin{array}{l}\text { Inserting and explaining scientific evidence on efficacy } \\
\text { and safety of intervention in literature review. }\end{array}$ \\
\hline & $\begin{array}{l}\text { Failure to balance the benefits / risks of unapproved } \\
\text { interventions for patients. } \\
\text { The benefits to the patients or the future community } \\
\text { are not clear. }\end{array}$ & $\begin{array}{l}\text { After obtaining informed consent, the researcher is } \\
\text { allowed to enter only those patients into the study } \\
\text { whose clinical condition worsened, despite receiving } \\
\text { treatment protocols notified by the Ministry of Health. }\end{array}$ \\
\hline & & Disclosing potential benefits for the community. \\
\hline \multirow[t]{4}{*}{$\begin{array}{l}\text { Research subject compensation or } \\
\text { reimbursement of costs }\end{array}$} & $\begin{array}{l}\text { The PI/funder has not provided compensation to } \\
\text { participants for the potential serious adverse events. }\end{array}$ & $\begin{array}{l}\text {-According to chapter } 2 \text { of the ethics guidelines for } \\
\text { clinical trials, the author is responsible for compensat- } \\
\text { ing patients. Thus, the author is supposed to commit to } \\
\text { obtain the accident insurance policy from the sponsor of } \\
\text { the project and submit it to the Research Ethics Com- } \\
\text { mittee. }\end{array}$ \\
\hline & & $\begin{array}{l}\text {-All clinical trial participants are covered by financial } \\
\text { sponsors, which are usually pharmaceutical companies. }\end{array}$ \\
\hline & & $\begin{array}{l}\text {-Lack of conflict of interest of the researcher shall be } \\
\text { ascertained by the committee. }\end{array}$ \\
\hline & $\begin{array}{l}\text { Risk of coercion regarding the fact that patients } \\
\text { participate only due to economic issues and reim- } \\
\text { bursement of costs. }\end{array}$ & $\begin{array}{l}\text {-Review of ethical issues by ethics committee. } \\
\text {-Making all treatments free of charge for patients with } \\
\text { Coronavirus disease by the Ministry of Health. }\end{array}$ \\
\hline $\begin{array}{l}\text { Process of obtaining informed } \\
\text { consent }\end{array}$ & $\begin{array}{l}\text { Incomplete insertion of the process of obtaining } \\
\text { informed consent. }\end{array}$ & $\begin{array}{l}\text { Writing down the time, place, and the person who ex- } \\
\text { plains information about the project to patients or their } \\
\text { families. Stating the way how to get an alternative } \\
\text { decision-maker to consent to patient participation in } \\
\text { research, when the patient is not qualified to give in- } \\
\text { formed consent. }\end{array}$ \\
\hline
\end{tabular}

the scientific reviewer, cost reviewer and ethics reviewer, the proposals were modified by the authors and finally approved. Several proposals of the clinical trial group had challenging ethics reviews regarding their consent documents. These consent issues and recommended solutions are presented in Table 3.

\section{Discussion and Conclusion}

Research ethics committees are comprised of policymakers, supervisors, and decision-makers and aim at increasing adherence to professional ethics standards in conducting health-related research. The existential philos- ophy of these committees is to preserve the patients' health, maintain and promote public trust in health care providers, protect the rights of both patients and health care providers, and promote organizational ethics. These committees strive to accomplish their mission comprehensively in a wide variety of ways. The main goals of these committees are as follow: considering human principles and values in health research; informing people about their rights as patients and their social responsibilities; protecting human dignity and rights of patients as stated in the Declaration of Helsinki and in Ethics Guideline for Research on Iranian Human Subjects; and monitoring, 
Table2. Workgroups and study types

Workgroups and study types

Epidemiology and public health research

Number

Clinical research

Basic science and virology research

Research into staff health maintenance, particularly mental and educational health

Table 3. Reviewer/committee concerns regarding consent document and recommended solutions

Criteria for consent document

Purpose of research

Study procedures

Disclosure of potential risk/burden

Disclosure of benefits Reviewer/committee concern

Study information is stated in a way that therapeutic misconception may occur.

Participation stages are not clearly described. The type of intervention and how the patient cooperates are not properly stated.

The research risks are not fully explained. (Necessity to properly address the risks and possible side effects).

Recommended solutions
Providing the patient with ample opportunity to con-
sult before making a decision.

The type of research intervention and patient collaboration should be clearly stated both in the proposal and in the informed consent.

- The forms of informed consent and the report of adverse events will be examined by the ethics committee in research.

-Accurate evaluation of the risks and possible complications of the research by experts.

Accurate evaluation and scientific review of the suggested treatment by scientific referees collaborating with the research ethics committee. influence through persuading the individuals to participate in research to identify and discover new Coronavirus treatment without having sufficient evidence. supervising, and evaluating of the researches.

In addition, the committees provide a valuable help in addressing ethical challenges in research environments and raising awareness and ethical sensitivity of all stakeholders toward ethical aspects of research. Also, they aim to provide, maintain, and improve mutual trust between researchers and research participants while conducting the research. Moreover, they maintain credibility and reputation of the research advocates as an ethical social institution and promote the concepts of professional commitment.

With regard to the importance of ethical decisionmaking in medical research, having basic solutions to solve researchers' problem is essential $(4,5)$. Ethics guidelines facilitate this by streamlining the decisionmaking process.

Using the right framework requires examining the specific conditions of the epidemic (6), which makes the decision-making much easier.

This article is a report of the performance of the IUMS COVID-19 research committee during the COVID-19 pandemic, which has been supported by using the common international research ethics guidelines (7-9) and substantiated with the experience of several years of ethical reviewing of research proposals and supervising research projects at the Iran University of medical sciences. To achieve the above goals, and given that the country has been managing and fighting the Coronavirus epidemic, Iran University of Medical Sciences, through convening 6 specialized sessions and weekly professional sessions, has reviewed all the research proposals currently underway and has tried to tackle all the scientific and ethical challenges ahead.

This report also presents the ethical challenges existing in research proposals and provides applicable strategies to tackle them (Table 1). Furthermore, specific ethical challenges associated with informed consent are stated and strategies for addressing them are suggested (Table 3).

To provide robust scientific review of the submitted proposals, research works are classified and evaluated in 4 specialized groups: staff mental health maintenance and educational interventions, epidemiological and public health research, basic science and virology research, and clinical trials (Table 2).

There are several studies in line with our work; for example, a paper which reports the experience of the Médecins Sans Frontier's (MSF) ethics review board on the Ebola epidemic in 2014-2015, categorized the research studies into clinical trial, vaccine production, diagnostic measures, and optimal treatment for ethics review. In their paper, studies are ethically discussed based on inclusion of vulnerable groups, like pregnant women, having qualitative methodology and using extra blood samples (10).

\section{Acknowledgment}

The authors would like to thank the secretariat of the Iran National Committee for Ethics in Biomedical Research for giving helpful advice during early days of COVID-19 pandemic. The authors are also very grateful to the other members of IUMS COVID-19 research committee whose contributions did not fulfill the authorship criteria but played an important role in managing COVID19 research in the IUMS.

\section{Conflict of Interests}

Jalil Koohpayehzadeh holds the position of the Chancellor of the Iran University of Medical Sciences \& Seyed Abbas Motevalian holds the position of the ViceChancellor for Research and Technology at the Iran University of Medical Sciences. The rest of the authors 
declare that there is no conflict of interest.

\section{References}

1. "Official Statistics of Coronavirus in Iran". http://www.newcorona.ir/

2. https://khabarfarsi.com/u/82562631

3. https://www.irna.ir/subject/83681341

4. Mezinska S, Kakuk P, Mijaljica G, et al. Research in disaster settings: asystematic qualitative review of ethical guidelines. BMC Med Ethics. 17, 62(2016).

5. Tansey CM, Herridge MS, Heslegrave RJ, Lavery JV. A framework for research ethics review during public emergencies. CMAJ. 2010;182(14):1533-1537.

6. Sethi N. Research and Global Health Emergencies: On the essential role of best practice. Pub Health Ethics. 2018;11(3):237-250.

7. Research Ethics in International Epidemic Response WHO Technical Consultation Geneva, Switzerland10-11 June 2009. https://www.who. int/ethics/gip_research_ethics_.pdf

8. Hunt MR, Anderson JA, Boulanger RF. Ethical implications of diversity in disaster research. Am J Disaster Med. 2012;7(3):211-21.

9. Tansey CM, Herridge MS, Heslegrave RJ, Lavery JV. A framework for research ethics review during public emergencies. Can Med Assoc J. 2010;182(14):1533-7.

10. Schopper D, Ravinetto R, Schwartz L, et al. Research Ethics Governance in Times of Ebola. Pub Health Ethics. 2017;10(1):49-61. 